\title{
Room-Temperature Ferromagnetism in Zn-Mn-O, X-Ray Photoemission Surface Study
}

\author{
D. Milivojević ${ }^{a, *}$, B. Babić-Stojić ${ }^{a}$, J. BlanušA ${ }^{a}$ And J. KovaĆ $\check{C}^{b}$ \\ ${ }^{a}$ Vinča Institute of Nuclear Sciences, University of Belgrade, P.O.Box 522, Belgrade, Serbia \\ ${ }^{b}$ Jožef Stefan Institute, Department for Materials Synthesis, Jamova 39,1000 Ljubljana, Slovenia
}

Room temperature ferromagnetic properties of $\mathrm{Zn}-\mathrm{Mn}-\mathrm{O}$ show evident dependence on manganese concentration and preparation conditions. We systematically studied series of samples with manganese concentration ranging from 0 to 10 at.\%, prepared in air at thermal treatment temperatures ranging from 400 to $900{ }^{\circ} \mathrm{C}$. The samples were investigated by X-ray diffraction, TEM, magnetization measurements and XPS spectroscopy. XPS analyses of surface composition, chemical bonding and XPS depth profiling were successfully employed on powder revealing the chemical composition at the surface of the grains and underneath. The study emphasizes important role of the grain surface in observed room temperature ferromagnetism. It seems that the ferromagnetic phase is correlated with oxygen build up at the surface.

PACS: 75.50.Pp, 81.40.Rs, 81.70.Jb, 82.80.Pv

\section{Introduction}

Strong interactions between $s$ and $p$ electrons and $d$ electrons could be used in a single semiconductor and new (spintronic) devices could be created. In attempts to develop such spintronic devices much effort has been made to find ferromagnetic semiconductors that exhibit ferromagnetism above room temperature (RT). Dietl et al. predicted the existence of ferromagnetism with a Curie temperature $T_{\mathrm{C}}$ above RT in $p$-type $\mathrm{ZnO}$ and $\mathrm{GaN}$ doped with Mn [1]. Further works brought disagreement about both the existence and the origin of RT ferromagnetism. Major dilemma is finding of ferromagnetism in Mn-doped $\mathrm{ZnO}$ which naturally grows as $n$-type [2]. Magnetism in $\mathrm{ZnO}: \mathrm{Mn}$ depends on Mn concentration, temperature and time of thermal treatment, precursors and on method and environment of preparation. The maximum of ferromagnetic parameters are usually obtained for the samples thermally treated at about $T=500{ }^{\circ} \mathrm{C}$, and for concentrations close to $1 \%[3,4]$.

We have studied structural and magnetic properties of the Zn-Mn-O samples prepared by thermal treatment in air at various temperatures and concentrations of manganese. Emphasis is put on the study of surface properties and correlation with ferromagnetism.

\section{Experimental details}

Polycrystalline samples of $\mathrm{Zn}-\mathrm{Mn}-\mathrm{O}$ were prepared by a solid state reaction method using $\mathrm{ZnC}_{2} \mathrm{O}_{4} \cdot 2 \mathrm{H}_{2} \mathrm{O}$ (99.999\%, Alfa Aesar) and $\mathrm{MnC}_{2} \mathrm{O}_{4} \cdot 2 \mathrm{H}_{2} \mathrm{O}$ (99\%, Alfa Aesar) as starting materials. Appropriate amounts were mixed, pressed into pellets and calcinated at $400{ }^{\circ} \mathrm{C}$ for 5

\footnotetext{
* corresponding author; e-mail: dusanm@vinca.rs
}

$\mathrm{h}$ in air. The calcined samples were reground, pelletized and thermally treated for $12 \mathrm{~h}$ in air. We prepared series of $\mathrm{Zn}-\mathrm{Mn}-\mathrm{O}$ samples treated at different temperatures and with the same nominal manganese concentration $x=1$ at $\%$, and a series of samples with various manganese concentration $x=0,1,2,4$ and 10 at $\%$ thermally treated at the same temperature $500{ }^{\circ} \mathrm{C}$. The samples are labeled as SX Y Y, where $\mathrm{X}$ is the Mn concentration in at $\%$ and $\mathrm{Y}$ is the thermal treatment temperature in Celsius divided by 100 .

Powder X-ray diffraction (XRD) spectra were recorded on a Philips PW 1050 diffractometer using $\mathrm{CuK}_{\alpha}$ radiation. XRD spectra were measured with a step size $(2 \theta)$ of $0.02^{\circ}$ at a slow scan rate of $60 \mathrm{~s} / \mathrm{step}$. Transmission electron microscopy (TEM) measurements of Zn-Mn-O samples were carried out using a Philips EM 400 instrument with operating voltage $120 \mathrm{kV}$. The magnetization measurements were carried out on a SQUID magnetometer (MPMS XL-5, Quantum Design).

The X-ray photoelectron spectroscopy (XPS or ESCA) analyses were carried out on a Physical Electronics PHITFA XPS spectrometer. The analyzed depth was about 1-3 nm. High-energy resolution spectra were acquired at energy resolution of $0.65-1.5 \mathrm{eV}$. The XPS spectra were aligned by setting the $\mathrm{C}-\mathrm{C}$ peak in the $\mathrm{C} 1 s$ spectrum to $284.8 \mathrm{eV}$ [5].

\section{Results and discussion}

Three measured samples show hysteresis at room temperature: S1_5 $\left(H_{c}=800 \mathrm{Oe}, M_{r}=0.0050 \mathrm{emu} / \mathrm{g}\right.$, $\left.M_{\mathrm{s}}=0.0195 \mathrm{emu} / \mathrm{g}=0.03 \mu_{\mathrm{B}} / \mathrm{Mn}\right), \mathrm{S} 1 \_4\left(H_{c}=80\right.$ Oe, $M_{r}=0.00006 \mathrm{emu} / \mathrm{g}, M_{\mathrm{s}}=0.0004 \mathrm{emu} / \mathrm{g}=$ $\left.0.0007 \mu_{\mathrm{B}} / \mathrm{Mn}\right)$ and $\mathrm{S} 4 \_5\left(H_{c}=40 \mathrm{Oe}, M_{r}=\right.$ $\left.0.0001 \mathrm{emu} / \mathrm{g}, M_{\mathrm{s}}=0.0014 \mathrm{emu} / \mathrm{g}=0.0006 \mu_{\mathrm{B}} / \mathrm{Mn}\right)$ (Fig. 1). Ferromagnetic component of the magnetization 
is obtained after subtracting the paramagnetic component from the total magnetization. There is no RT ferromagnetism (hysteresis) in the S10 5 and S1 9 samples. The $M(H)$ dependence for these samples is a linear function up to $50 \mathrm{kOe}$ indicating the paramagnetic origin of the magnetization at $300 \mathrm{~K}$.

XRD was performed on all samples. The difraction lines can be indexed as a mixture of phases, the major phase $\mathrm{ZnO}$, and minor phases $\mathrm{MnO}_{2}, \mathrm{Mn}_{3} \mathrm{O}_{4}$, $\mathrm{Zn}_{1-y} \mathrm{Mn}_{y} \mathrm{Mn}_{2} \mathrm{O}_{4}$ with tetragonal symmetry (I4 $1 /$ amd) and $\mathrm{ZnMn}_{2} \mathrm{O}_{4}$ with cubic symmetry $\left(\mathrm{Fd}_{3} \mathrm{~m}\right)$.

The XRD patterns in Fig. 2a show evolution of minority manganese oxides phases with increasing temperature of thermal treatment for the $x=1$ at $\%$ samples. The figure shows enlarged segment where the relevant and most intense peaks are. For the lowest temperature, $T=400{ }^{\circ} \mathrm{C}$, only $\mathrm{MnO}_{2}$ peak is clearly visible. Tetragonal $\mathrm{Zn}_{1-y} \mathrm{Mn}_{y} \mathrm{Mn}_{2} \mathrm{O}_{4}$ phase emerges at $T=500^{\circ} \mathrm{C}$, and cubic $\mathrm{ZnMn}_{2} \mathrm{O}_{4}$ emerges at $T=900{ }^{\circ} \mathrm{C}$. With increasing temperature the intensities of impurity lines increase and the lines are getting sharper.

The XRD patterns in Fig. 2b show evolution of minority manganese oxides phases with increasing manganese concentration for the samples thermally treated at $T=500{ }^{\circ} \mathrm{C}$. In these samples only $\mathrm{MnO}_{2}$ and tetragonal $\mathrm{ZnMn}_{2} \mathrm{O}_{4}$ phase can be observed. With increasing manganese concentration $\mathrm{ZnMn}_{2} \mathrm{O}_{4}$ phase develops while $\mathrm{MnO}_{2}$ phase decays.

These results show that phase impurities are not the origin of ferromagnetism.

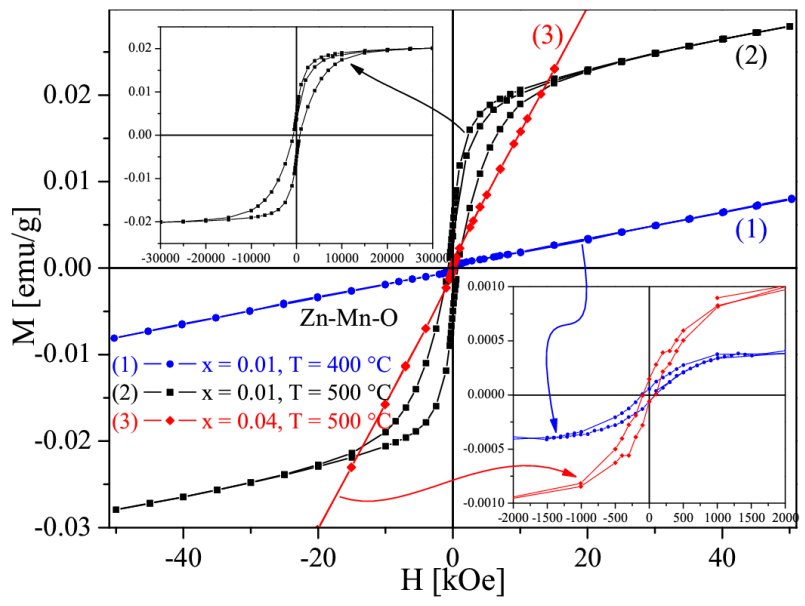

Fig. 1. $\mathrm{M}(\mathrm{H})$ curves for the samples $\mathrm{S} 14$ (1), S1 5 (2) and S4_5 (3). The insets - details after subtracting the paramagnetic contribution.

The average $\mathrm{ZnO}$ crystallite size determined using Scherrer's formula increases with increasing sintering temperature: $d \approx 30,53,72,74$ and $102 \mathrm{~nm}$ for the $x=1$ at $\%$ sample thermally treated at 400, 500, 600, 700 and $900{ }^{\circ} \mathrm{C}$ respectively. The average $\mathrm{ZnO}$ crystallite size for the samples treated at $500{ }^{\circ} \mathrm{C}$ decreases with increasing manganese concentration: $d \approx 54,53,52,44$

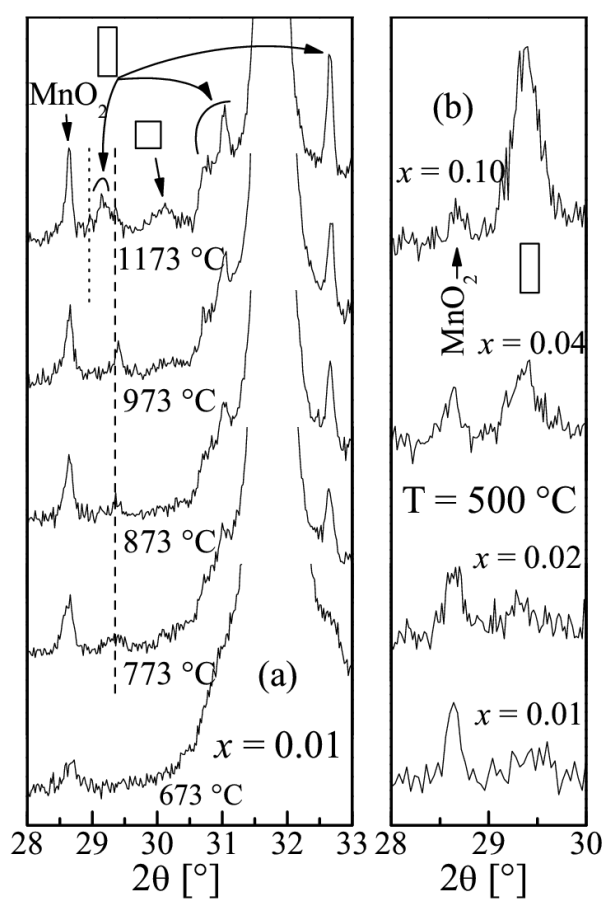

Fig. 2. XRD patterns segment: a) $x=0.01$ samples treated at various temperatures, and $\mathrm{b}$ ) samples treated at $T=500{ }^{\circ} \mathrm{Cfor}$ various concentrations of $\mathrm{Mn}$. П - tetragonal $\mathrm{Zn}_{1-y} \mathrm{Mn}_{y} \mathrm{Mn}_{2} \mathrm{O}_{4}, \square$ - cubic $\mathrm{ZnMn}_{2} \mathrm{O}_{4}$ peaks.

and $35 \mathrm{~nm}$ for $x=0,1,2,4$ and 10 at\% respectively.

Typical bright field TEM image of the Zn-Mn-O S1 5 sample is shown in Fig. 3. The size of the $\mathrm{ZnO}$ crystallites with faceted morphology seen by TEM lies in the range $50-100 \mathrm{~nm}$ which is consistent with the result obtained from the XRD spectra.

Six representative samples S0 $5, \mathrm{~S} 1 \quad 5, \mathrm{~S} 4 \quad 5, \mathrm{~S} 10 \quad 5$, S1 4 and S1 9, were studied by XPS to determine surface composition, chemical bonding and depth distribution of elements in subsurface region. The samples were in the form of pressed powder. Fig. 4 shows XPS survey spectra. The peaks identified are: $\mathrm{Zn} 2 p_{3 / 2}$, Zn $2 p_{1 / 2}$, Zn LMM, Zn $3 \mathrm{~s}, \mathrm{Zn} 3 \mathrm{p}, \mathrm{O} 1 s, \mathrm{C} 1 s$ and Mn $2 p_{3 / 2}$. Table shows the compositions determined by XPS and also difference between $\mathrm{O}$ and $\mathrm{Zn}$ concentrations $(\mathrm{O}-\mathrm{Zn})$, contributions of carbon components and average $\mathrm{ZnO}$ crystallite size $d$ determined by XRD.

In all spectra the Mn $2 p$ signal was very low. It is not expected, but was reported also by other researchers [6, 7]. It should indicate that $\mathrm{Mn}$ penetrates inside the $\mathrm{ZnO}$ grains, but depth profiling did not show any significant enrichment of $\mathrm{Mn}$ inside. In that spectral region similar structure exists even for the sample without Mn, so the interpretation could not be reliable. Therefore, the Mn was not considered in the calculation of concentrations.

The energy of the $\mathrm{Zn} 2 p_{3 / 2}$ peak is at $1021.8 \mathrm{eV}$. The FWHM of the peak is $1.55 \mathrm{eV}$ and shows the good spec- 


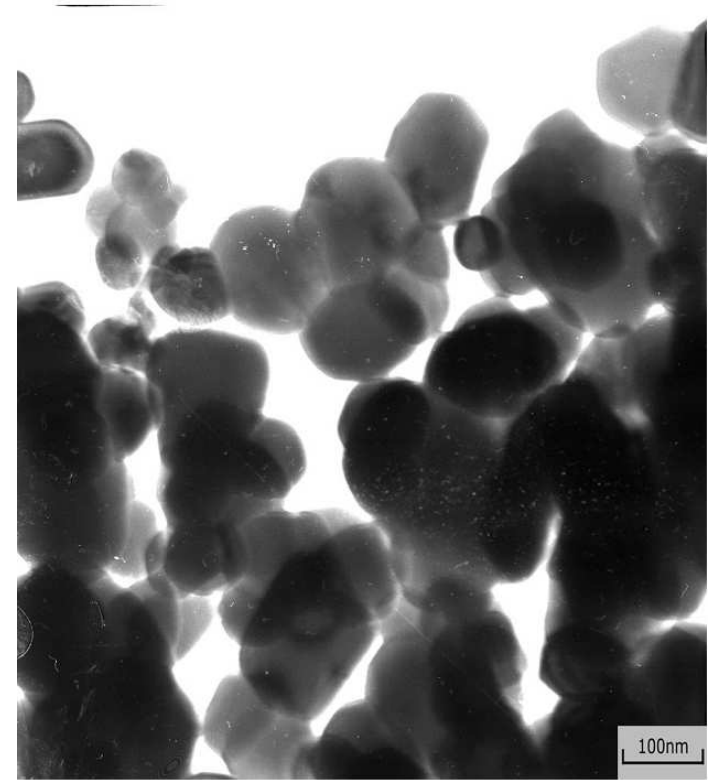

Fig. 3. TEM micrograph of the S1_5 sample.

tral resolution obtained. Normalized Zn $2 p_{3 / 2}$ for all the samples spectra are shown on Fig. 5. All the spectra mainly coincide except S1_9 and S10 5 .

The $\mathrm{O} 1 s$ peak is at $530.2 \mathrm{eV}$. The $\overline{\mathrm{F}} \mathrm{WHM}$ is $1.22 \mathrm{eV}$. The peak was fitted with two components at $530.4 \mathrm{eV}$ and $532.0 \mathrm{eV}$. The first peak at $530.4 \mathrm{eV}$ is, according to the literature, unambiguously assigned to lattice oxygen atoms $\mathrm{O}^{2-}$ in the $\mathrm{ZnO}$ matrix $[7,8]$. The second peak cannot be assigned to adsorbed oxygen-based species, because the depth profiling showes that peak shape of S0_5 and S1_5 samples did not change with sputtering, when the subsurface region was analysed and O-based adsorbates were supposed to be removed (Fig. 6). Insets in Fig. 6 show XPS spectra of $\mathrm{O} 1 s$ line, for the samples $\mathrm{S} 0 \_5, \mathrm{~S} 1 \_5, \mathrm{~S} 1 \_9$ and $\mathrm{S} 10 \_5$, before and after the sputtering. The spectrum of sputtered $\mathrm{S}_{-} 5$ is added to all the spectra for comparison. The $\mathrm{O} 1 \mathrm{~s}$ spectra of nonferromagnetic samples S1_9 and S10_5 differ from other samples, but after the sputtering, these spectra change to a large extent, getting closer to some referent spectrum. It shows that the spectrum of clean $\mathrm{ZnO}$ surfaces consists of two peaks with peak surface areas to be about $25 \%$ for $532.0 \mathrm{eV}$ peak, and $75 \%$ for $530.4 \mathrm{eV}$ peak. In order to understand the origin of the peak at $532.0 \mathrm{eV}$ we should bear in mind that $\mathrm{ZnO}$ has Zn-polar, O-polar and non-polar surfaces. $\mathrm{Zn}$ and $\mathrm{O}$ at the polar surfaces bind polarization charges, electrons and holes respectively. On the other hand, it is shown that the peak at that position nearly disappears by annealing in oxygen [7], which ultimately give rise to O-terminated surfaces. Thus, we suggest that it is possible that $\mathrm{O} 1 \mathrm{~s}$ line at $532.0 \mathrm{eV}$ originates from oxygen being in the layer just under the Zn at outmost surface. In that case electric field around oxygen due to charged outmost $\mathrm{Zn}$ is disturbed, which moves XPS line. When annealing in oxygen is applied, $\mathrm{O}$ bonds to $\mathrm{Zn}$ at outmost surface (O-terminate it) and symmetry around inner oxygen is restored. From Fig. 6 one can see that the relative intensity of contribution at $532.0 \mathrm{eV}$ is lower for ferromagnetic samples, which means more oxygen (less zinc) at the surface comparing with non-ferromagnetic samples.

TABLE

Surface concentrations of elements in at.\%. $d$ is average crystallite size.

\begin{tabular}{|c|c|c|c|c|c|c|c|c|c|c|c|c|c|}
\hline Sample & $T\left[{ }^{\circ} \mathrm{C}\right]$ & $x[\%]$ & $\mathrm{C}$ & $\mathrm{O}$ & $\mathrm{Zn}$ & $\mathrm{C}(289.5) / \mathrm{C}$ & $\mathrm{C}(284.8) / \mathrm{C}$ & $\mathrm{d}[\mathrm{nm}]$ & $\mathrm{C}(289.5)$ & $\mathrm{C}(284.8)$ & $3 \cdot \mathrm{C}(289.5)$ & $\mathrm{O}-\mathrm{Zn}$ & FM \\
\hline $\begin{array}{l}\text { So_5 } \\
\end{array}$ & 500 & 0 & 14.5 & 48.4 & 37.1 & 11.8 & 88.2 & 54 & 1.71 & 12.79 & 5.13 & 11.37 & - \\
\hline $\mathrm{S} 1 \quad 5$ & 500 & 1 & 7.3 & 49.2 & 43.5 & 26.4 & 73.5 & 53 & 1.93 & 5.37 & 5.79 & 5.68 & Yes \\
\hline $\mathrm{S} 4 \_5$ & 500 & 4 & 7.9 & 49.8 & 42.3 & 30.5 & 69.5 & 44 & 2.42 & 5.52 & 7.27 & 7.49 & Yes \\
\hline $\mathrm{S} 10 \_5$ & 500 & 10 & 10.7 & 52.9 & 36.4 & 46.2 & 53.8 & 35 & 4.93 & 5.74 & 14.79 & 16.53 & No \\
\hline $\mathrm{S} 1 \_4$ & 400 & 1 & 6.7 & 50.6 & 42.7 & 39.5 & 60.5 & 30 & 2.64 & 4.05 & 7.93 & 7.88 & Yes \\
\hline $\mathrm{S} 19$ & 900 & 1 & 32.7 & 42.4 & 24.9 & 15.8 & 84.2 & 102 & 5.17 & 27.54 & 15.50 & 17.49 & No \\
\hline
\end{tabular}

XPS spectra of C $1 s$ line consist of well separated two components. The first one is at $284.8 \mathrm{eV}$ and represents $\mathrm{C}-\mathrm{C} / \mathrm{C}-\mathrm{H}$ bonds due to layer of adventitious carbon. The second peak at about $289.5 \mathrm{eV}$ we assign to carbonate phase $\left(\mathrm{CO}_{3}^{2-}\right)$.

Concentration of excess oxygen $(\mathrm{O}-\mathrm{Zn})$ correlates with concentration of carbon from carbonate phase with ratio of 3 (Table) which matches well with $\mathrm{CO}_{3}$ ion. Better correlation (ratio closer to 3 ) is found for the samples with less carbon. Sample S0_5 deviates from the correlation and it is probably because non-carbonate carbon, which is dominant in this sample, also contains some oxygen. That is the reason why in the samples with higher percentage of $\mathrm{C}(284.8)$ carbon, the difference between $\mathrm{O}$ 
and $\mathrm{Zn}$ concentration $(\mathrm{O}-\mathrm{Zn})$ overvalues $3 \mathrm{C}(289.5)$. It can be expected that carbonate ion $\left(\mathrm{CO}_{3}^{2-}\right)$ likely bonds to the dangling-bond of $\mathrm{Zn}$ on $\mathrm{Zn}$ polar surface reducing polarity, rather then exchanging with strongly bonded $\mathrm{O}$ on the $\mathrm{O}$ polar surface, otherwise ratio $(\mathrm{O}-\mathrm{Zn}) / \mathrm{C}(289.5)$ would be closer to factor 2 .

The surface carbonate concentration $\mathrm{C}(289.5)$, is 3 times lower for ferromagnetic samples comparing with non-ferromagnetic (Table). We assume that the state of the surfaces is responsible for ferromagnetism, and that surfaces which promote ferromagnetism are for some reason less susceptible to carbonate growth. We believe that ferromagnetic samples have more $\mathrm{O}$ terminated surfaces that are not suitable for carbonate growth. This is in accordance with the fact that annealing in oxygen atmosphere switches on the ferromagnetism, while annealing in nitrogen switches it off [9]. These findings are also in accordance with our discussion about $\mathrm{O} 1 s$ spectrum.

The in-depth composition of four samples S0_5, S1 5, S10 5 and S1 9 was analysed by the XPS depth profiling. Obtained depth XPS profiles are presented in Fig. 6. The sputtering rate was about $1.0 \pm 0.3 \mathrm{~nm} / \mathrm{min}$. From reported depth profiles in Fig. 6 it follows that the powders are partially covered by 1-2 nm thick carbon-based layer.

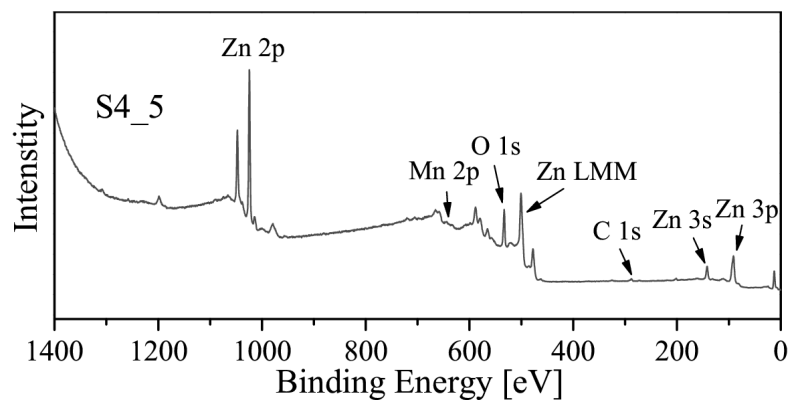

Fig. 4. XPS survey spectra obtained on the sample S4_5.

In the inner part of the grains the ratio of $\mathrm{Zn}$ and $\mathrm{O}$ is close to $50 \%: 50 \%$ for S0_5 and deviate from stochiometry as the concentration of $\mathrm{Mn}$ increases.

XPS depth profiles show that the surface region is depleted in $\mathrm{Zn}$ with respect to $\mathrm{O}$. Pure $\mathrm{ZnO}$ naturally grows as $n$-type semiconductor with excess $Z n$. Zn depletion at the surface region $(1-5 \mathrm{~nm})$ promotes $p$-type defects at and near the grain boundaries. Also, analysis of $\mathrm{O} 1 \mathrm{~s}$ and $\mathrm{C} 1 s$ spectra shows more oxygen terminated surfaces for ferromagnetic samples. O polar surface can be predicted to have $p$-type conductivity [10]. According to Dietl et al., $p$-type free carriers induce ferromagnetic ordering between $\mathrm{Mn}$ ions in $\mathrm{ZnO}$ [1]. However, grain core and Zn-polar surface compensate influence of oxygen at the surface, and also some $\mathrm{Mn}$ is in the form of non-ferromagnetic manganese oxides. Therefore, only a small fraction of $\mathrm{Mn}$ ions participates in RT ferromagnetic ordering, resulting in the very small $M_{s}$. We can

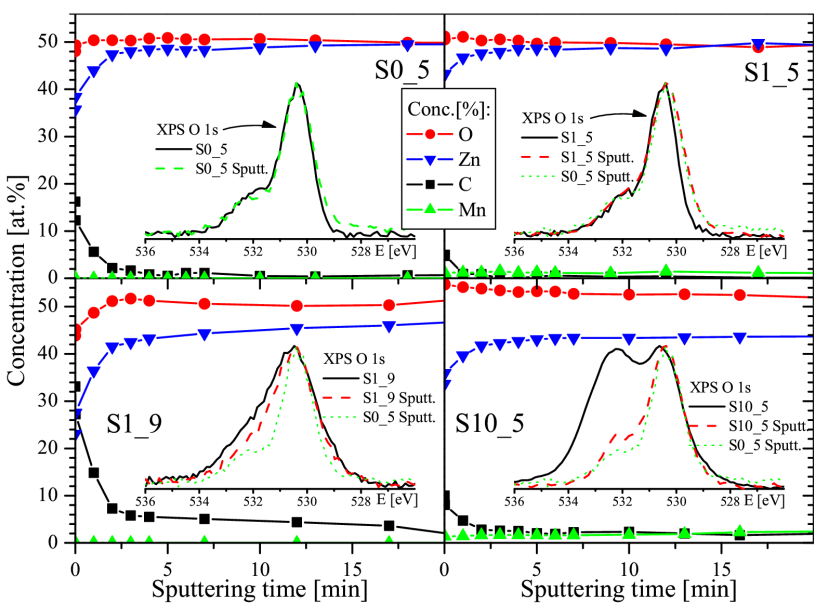

Fig. 5. Zn $2 p_{3 / 2}$ XPS spectrum of all six samples. The spectra are normalized and aligned for comparison.

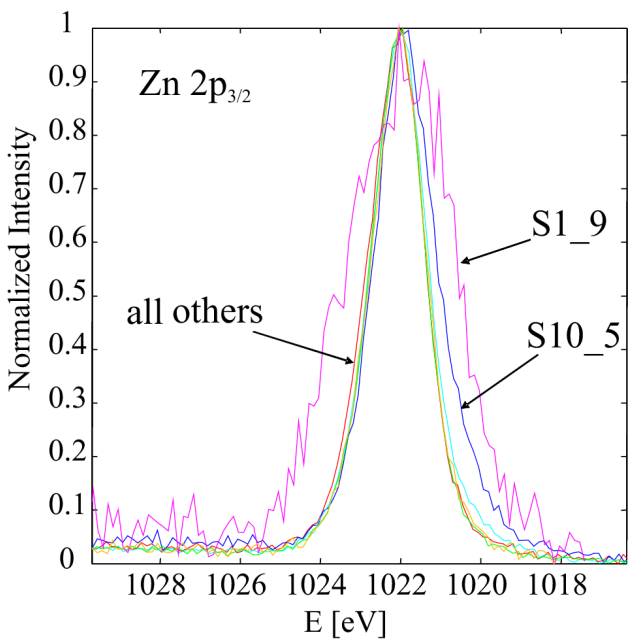

Fig. 6. XPS depth profiles obtained for the samples S0_5, S1_5, S1_9 and S10_5. Insets: XPS O $1 s$ spectra for respective samples, before sputtering and after sputtering (30 nm depth, denoted "sputt."). The spectra are normalized and aligned. Spectrum of sputtered S0_5 is for comparison.

expect that ferromagnetism can be developed in samples with smaller grain size, that have higher grain surface to volume ratio, which indeed was undoubtedly shown in the Straumal et al. work [11].

Zinc depletion at the surfaces and $\mathrm{O}$ terminated surfaces are less stable at higher temperatures. Higher temperature treatment relaxes defects, increases the size of the grains, agglomerates manganese atoms and changes Mn ionization state, as seen from XRD, and therefore obstructs ferromagnetism and establishes antiferromagnetic interactions. Higher Mn concentration obstructs ferromagnetism in three ways, first, by forming of other phases, like observed $\mathrm{ZnMn}_{2} \mathrm{O}_{4}$, second, higher probability for $\mathrm{Mn}$ ions to interact antiferromagnetically and 
third, higher concentration of Mn requires higher concentration of holes to establish ferromagnetism [12].

There is evidently the correlation between oxygen at the surface and high-temperature ferromagnetism in the Zn-Mn-O samples, but exact mechanisms, that could relate state of the surface and ferromagnetism, are yet to be investigated, especially when even the physics of $\mathrm{ZnO}$ surfaces is still an hot issue [13].

\section{Acknowledgments}

Financial support for this study was granted by the Ministry of Science of the Republic of Serbia, project No 172026, and by the Slovenian Research Agency within the frame of a Programme P2-0082. The authors thank Tatjana Filipič for help in the XPS measurement.

\section{References}

[1] T. Dietl, H. Ohno, F. Matsukura, J. Cibert, D. Ferrand, Science 287, 1019 (2000).

[2] U. Ozgur, Ya.I. Alivov, C. Liu, A. Teke, M.A. Reshchikov, S. Dogan, V. Avrutin, S.J. Cho, H. Morkoc, J. Appl. Phys. 98, 041301 (2005).

[3] P. Sharma, A. Gupta, K.V. Rao, F.J. Owens, R. Sharma, R. Ahuja, J.M. Osorio Guillen, B. Johansson, G.A. Gehring, Nat. Mater. 2, 673 (2003).
[4] B. Babić-Stojić, D. Milivojević, J. Blanuša, V. Spasojević, N. Bibić, B. Simonović, D. Aranđelović, J. Phys.: Condens. Matter 20, 235217 (2008).

[5] J.F. Moulder, W.F. Stickle, P.E. Sobol, K.D. Bomben, Handbook of X-Ray Photoelectron Spectroscopy (Physical Electronics Inc., Eden Prairie, Minnesota, USA, 1995).

[6] O.D. Jayakumar, C. Sudakar, A. Vinu, A. Asthana, A.K. Tyagi, J. Phys. Chem. C113, 4814 (2009).

[7] X.Q. Wei, B.Y. Man, M. Liu, C.S. Xue, H.Z. Zhuang, C. Yang, Physica B 388, 145 (2007).

[8] L. Li, L. Fang, X.J. Zhou, Z.Y. Liu, L. Zhao, S. Jiang, J. Electron. Spectrosc. Relat. Phenom. 173, 7 (2009).

[9] D. Rubi, J. Fontcuberta, A. Calleja, Ll. Aragones, X.G. Capdevila, M. Segarra, Phys. Rev. B75, 155322 (2007).

[10] C. Zhou, J. Kang, J. Mater. Sci.: Mater. Electron 19, S229 (2008).

[11] B.B. Straumal, A.A. Mazilkin, S.G. Protasova, A.A. Myatiev, P.B. Straumal, G. Schutz, P.A. van Aken, E. Goering, B. Baretzky, Phys. Rev. B79, 205206 (2009).

[12] K. Sato, H. Katayama-Yoshida, Semicond. Sci. Technol. 17, 367 (2002).

[13] J. Goniakowski, F. Finocchi, C. Noguera, Rep. Prog. Phys. 71, 016501 (2008). 